\title{
Texture and texture assessment of thickened fluids and texture-modified food for dysphagia management
}

\author{
Enrico K. Hadde, Jianshe Chen ${ }^{*}$ \\ Lab of Food Oral Processing, School of Food Science and Biotechnology, Zhejiang Gongshang University, \\ Hangzhou, Zhejiang, China
}

* Corresponding author

Email: jschen@zjgsu.edu.cn

Tel: (00)86 57128008904

This is the author manuscript accepted for publication and has undergone full peer review but has not been through the copyediting, typesetting, pagination and proofreading process, which may lead to differences between this version and the Version of Record. Please cite this article as doi: 10.1111/jtxs.12567

This article is protected by copyright. All rights reserved. 


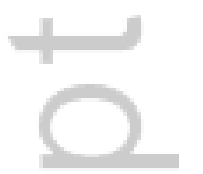

This article is protected by copyright. All rights reserved. 


\begin{abstract}
Thickened fluids and texture-modified foods are commonly used in the medical management of individuals who suffer from swallowing difficulty (known as dysphagia). However, how to reliably assess texture properties of such food systems is still a big challenge both to industry and to academic researchers. This article aims to identify key physical parameters that are important for objective assessment of such properties by reviewing the significance of rheological or textural properties of thickened fluids and texture-modified foods for swallowing. Literature reviews have identified that dominating textural properties in relation to swallowing could be very different for thickened fluids and for texture-modified foods. Important parameters of thickened fluids are generally related with the flow of the bolus in the pharyngeal stage, while important parameters of texture-modified foods are generally related with the bolus preparation in the oral stage. This review helps to identify key textural parameters of thickened fluids and texture-modified foods in relation to eating and swallowing and to develop objective measuring techniques for quality control of thickened fluids and texture-modified foods for dysphagia management.
\end{abstract}

Keywords: dysphagia, thickened fluids, food texture, texture modification, swallowing, rheology

This article is protected by copyright. All rights reserved. 


\section{Introduction}

Dysphagia is defined as a medical condition that affects safety, efficiency, and/or quality of eating and drinking (Whelan, 2001, Logemann, 1998). Patients who suffer from dysphagia are likely to reduce dietary intake as a result of the condition which may in turn cause malnutrition and dehydration. Other concerns may include aspiration pneumonia and asphyxiation (Althaus, 2002, Atherton et al., 2007) It affects individuals of all ages from infants to the elderly, with the majority of patients being elderly who face swallowing difficulties due to illness, polypharmacy and weakened reserves of eating capability (Barczi et al., 2000, Cabre et al., 2010). Dysphagia usually occurs when a person has difficulty in moving food or drink to the back of the mouth to be swallowed and/or through the pharynx and safely past the airway. Normally, when the bolus is swallowed and enters the pharyngeal area, a valve that separates the pharynx from the larynx is closed to ensure the bolus remains in the pharynx and enters oesophagus but does not enter the trachea. However, this valve often operates at a slower rate for people who suffer dysphagia. As a result, the bolus may enter the airpipe and cause aspiration (Logemann, 2007).

Texture-modified foods or thickened fluids play a major role in clinician's treatment of such patients (Leonard and Kendall, 2013, Steele, 2015). The term thickened fluids are usually referred for drink products (e.g. thickened water, thickened milk), while texture-modified foods are usually referred for food products in solid or soft solid form which require a certain extent of mastication during eating (e.g. puree, mashed potato). Thickened fluids flow more slowly, and thus slows down the swallowing process and increases pharyngeal transit time (Goldfield et al., 2013, Bingjie et al., 2010), allowing an adapted reflex response time while 
swallowing (Reimers-Neils et al., 1994). The modification of food texture compensates for chewing difficulties or fatigue, thus improve swallowing safety and avoid asphyxiation. These methods have become the most recommended by clinicians due to low cost and ease of implementation (Chen, 2009, Logemann, 2014).

Thickened fluids used in dysphagia management have been known as Thin $(0-50 \mathrm{cP})$, Nectar-like fluids (51 - 350 cP), Honey-like fluids (351 - 1750 cP) and spoon-thick fluids (>1750 cP) in North America, since the publication of National Dysphagia Diet (NDD) in 2002 (National Dysphagia Diet Task Force, 2002). Shear viscosity measurement at shear rate of $50 \mathrm{~s}^{-1}$ was recommended by NDD as a more precise measurement between thickness categories. However, implementation of NDD approach faced practical problems. Firstly, expensive machinery, such as rheometer and skilled personnel are necessary to perform accurate viscosity measurements which are not accessible to clinicians, carers or patients with dysphagia (Barbon and Steele, 2018). Secondly, the non-Newtonian behaviour of most dysphagia foods makes the choice of $50 \mathrm{~s}^{-1}$ questionable. The terminology that is used to describe thickened fluids for dysphagia management had been different in different countries. Each country has their own terminology and standardisation for thickened fluids and texture-modified foods. For example, the National Standardisation of Thickened Fluids in Australia is called Level 150 - Mildly Thick, Level 400 - Moderately Thick and Level 900 Extremely Thick. In Japan, it is called Level 1 Mildly Thick, Level 2 Moderately Thick and Level 3 Extremely Thick (Atherton et al., 2007, Funami, 2016). Although some of the terminologies may sound similar, the consistencies may not be similar. In 2013, International Dysphagia Diet Standardisation Initiative (IDDSI) developed a standardised way of naming 
and describing texture-modified foods and thickened fluids for people with dysphagia (Cichero et al., 2013). In 2017, a new international framework for classifying foods and drinks used in dysphagia management was published which consists of a continuum of 8 levels $(0-7)$, where drinks are measured from Level 0 to Level 4 , while foods are measured from Level 3 to Level 7 (Cichero et al., 2017). For thickened fluids, the fluids are categorised by their 'thickness' (e.g. Level 0 - Thin, Level 1 - Slightly thick, Level 2 - Mildly thick, Level 3 - Moderately thick and Level 4 - Extremely thick) and their ability in a gravity flow testing method using a syringe. An updated version of the complete IDDSI framework (detailed definitions) and testing methods have been released recently (Cichero et al., 2020). It should be noted that the term 'thickness' is a qualitative and descriptive term and usually used in sensory evaluation, referring to shear viscosity of the fluid.

On the other hand, texture-modified foods are categorised by their mechanical properties (e.g. hardness, cohesiveness, adhesiveness, etc.) and the geometrical attributes (e.g. size, shape), for example, for IDDSI Level 5, the particle size of the food should be no bigger than $4 \mathrm{~mm}$ width for adults and should not be sticky (Cichero et al., 2017). A review paper by Steele et al. (2015) reported that the properties of hardness, cohesiveness and slipperiness were important factors for consideration for texture-modified food. However, it was realised that a complex and expensive machinery such as Texture Analyzer is required to formally assess these mechanical properties. Therefore, an alternative practically feasible method for testing food size and texture was developed by IDDSI (see IDDSI website at www.iddsi.org for more details). 
The practical method for testing food texture and thickened fluids developed by IDDSI is widely welcomed by carers and patients because of its simplicity and reliability (Cichero et al., 2017). However, despite this method is well applicable for frontline applications, it is not most suitable for quality control purposes in labs both at manufacture site and research lab. Therefore, in the present paper, the significance of rheological or textural properties published in recent years in the field of dysphagia is discussed for their relevance to oral handling and swallowing to provide recommendations for instrumental techniques that can be used to quantify these parameters. It should be noted that hard solid foods are not discussed in this review because they are not typical food that are commonly consumed by dysphagia patients.

\section{Thickened fluids}

Liquids are typically thickened to slow their speed of transit through the oral and pharyngeal phases of swallowing, allowing better oral and pharyngeal coordination. When swallowed, it forms a cohesive bolus that have less risk to fracture to multiple droplets, allowing the fluid to flow safely into the oesophagus. A most important feature of fluid food is that it doesn't require chewing and mastication. Therefore, a fluid food tends to have a shorter stay in the oral cavity and, in many cases, it can be swallowed directly. The main concerns of the textural properties for such a food are those directly related to its flow behaviour during swallowing in particular in the pharyngeal phase. Study of rheology of thickened fluids is mostly designated to promote safe swallowing as part of dysphagia management (Hadde and Chen, 2019, Cichero et al., 2000). Rheological behaviour of thickened fluids can be divided into two deformations, shear deformation and extensional deformation. Rheology in shear 
deformation is often measured in shear viscosity which describes the fluid's thickness and more specifically its resistance to shear flow (Rao, 1977). On the other hand, rheology in extensional deformation is measured in extensional viscosity which describes the fluid's resistance to stretching/elongation.

\subsection{Shear viscosity and practical assessments}

Much of the literature has focused on the rheological behaviour of thickened fluids in shear deformation (Hadde et al., 2015b, Hadde et al., 2015c, Garcia et al., 2008, Sopade et al., 2007, Sopade et al., 2008a, Sopade et al., 2008b). The most well-known fact in the field of dysphagia is that shear viscosity is an important parameter for thickened fluids. It is believed that a higher shear viscosity slows down the flow of the bolus in the pharynx (NamasivayamMacDonald et al., 2018, Steele, 2015, Dantas et al., 1990, Miller and Watkin, 1996), thus led to longer transit time in the pharyngeal phase, allowing better oral and pharyngeal coordination and enhancement of safe swallowing (Robbins et al., 1992). This was supported by Taniguchi et al. (2008) and Newman et al. (2016) who observed that the total swallowing time and oral ejection time increased with the apparent shear viscosity.

Shear viscosity has been an established way of reporting flow properties in the field of dysphagia. Many testing methods are available to measure the shear viscosity of the fluid either directly via a precise instrument or indirectly via an empirical device. Shear rheometers are instruments that are commonly used in research labs to measure the shear viscosity of the fluid with fundamental precision. However, such an approach is not applicable for quality control purposes in industry due to the associated costs and skill training. In industry, a more feasible approach is by using empirical methods, such as the observation of flow across a flat, 
level surface over time, called slump tests. Line-spread test and Bostwick consistometry are examples of slump tests that are commonly used in hospital to assess the thickness consistency of thickened fluids for dysphagia diet (Barbon and Steele, 2018). One of the measuring techniques that were developed by IDDSI to assess Level $0-3$ liquids (IDDSI syringe flow test) is significantly affected by the shear viscosity of the fluid. However, a review paper by Hanson (2016) reported that fluid viscosity is only one of many factors affecting texture modification in practice. Other properties, such as slipperiness, roughness, cohesiveness, adhesiveness and many more may also be important for thickened fluid (Stokes et al., 2013). Recent studies showed that fluids with similar shear viscosity, but prepared using different thickeners can have significantly different perceptual characteristics (Hadde et al., 2020a, Ong et al., 2018).

Fluids used in dysphagia management are generally shear-thinning fluid with existence of an apparent yield stress for some of them. The degree of shear-thinning is dependent on the types of thickener and can be reflected by the value of the flow behaviour index $n$ (the smaller the $n$ value, the more shear thinning of the fluid. Xanthan gum-based thickener is usually more shear-thinning ( $n$ value could be as low as 0.1 ) than starch-based thickener ( $n$ value could be as low as 0.3 ). For example, a study conducted previously by one of the author revealed $n$ value of thickened fluids within the range of $0.16-0.39$ (Hadde, Nicholson \& Cichero, 2015). A recent study on the rheology of protein-based beverages using different food thickeners even observed a lower and narrower $n$ value of only $0.14-0.21$ (Kim \& Yoo, 2018). Despite of these studies, there is still not enough literature evidences to specify a suitable range of shear thinning for thickened fluids. Yield stress is defined as the minimum stress necessary to cause a flow to a fluid. Although it has not yet been proven, it is hypothesised that yield stress of the bolus is relevant for swallowing (Cho 
et al., 2012, Popa Nita et al., 2013). The total amount of tongue pressure required to initiate flow of the fluid for swallow reflexion, whilst primarily being determined by the viscous stresses at typical shear rates, may also be affected by the yield stress (Hadde et al., 2015a). On the related topic, the use of "fork drip test", one of the measuring techniques that is developed by IDDSI to measure the consistency for Levels 3 - 5, is based on the belief that it is not only viscosity that were measured to differentiate the fluid, but yield stress as well (Hadde et al., 2015a). Fork drip test measures the ability of the fluid to flow off the prongs/tines due to gravity.

\subsection{Cohesiveness and extensional viscosity and practical assessment}

The rheological properties of thickened fluids in shear deformation have been explored for many decades, but more recently the discussion has been focused around the rheological properties in extensional deformation of thickened fluids, on the recognition of the high relevance of extensional deformation to bolus flow (Chen and Lolivret, 2011). It was reported that for similar shear viscosity at $50 \mathrm{~s}^{-1}$, the extensional viscosity of the fluid was dependent on the type of thickener. The extensional viscosity of the gum-based thickeners is significantly higher than the starch-based thickeners (Hadde and Chen, 2019, Waqas et al., 2017, Brito-de la Fuente et al., 2017). Additionally, it was reported that the extensional viscosity of thickened fluids are also highly dependent on the dispersing media (Hadde et al., 2020b). Hadde et al. (2020b) observed that the extensional viscosity of thickened skim milk is lower than thickened water for a given amount of added thickener.

Even though both extensional rheology and shear rheology are about the deformation of fluid material, they are different in nature. In a shear deformation or a shear flow, particles or fluid 
elements tends to slide over each other under the action of the external shear force (see Figure 1A). However, an extensional flow tends to cause much stronger actions to particles or fluid elements. As can be seen in Figure 1B, particles or fluid elements on the same plane are pulled or stretched away from each other, but those on the next planes tend to move towards each other, causing much severer deformation than a shear flow. Because of their very different resistance against the flow, the values of the extensional viscosity and shear viscosity for a same fluid are also hugely different. The ratio between the extensional and shear viscosity is called Trouton ratio. For simple fluids (i.e. Newtonian), the apparent extensional viscosity is three times higher than the shear viscosity, but for non Newtonian fluids, the Trouton ratio could be much higher and usually increases with the viscoelasticity of the material, such as thickened fluids (Macosko, 1994). The apparent extensional viscosity of thickened fluids can be measured using a filament thinning devices, such as Capillary Breakup Extensional Rheometer (CaBER) (He et al., 2016, Hadde and Chen, 2019). However, such an approach is only suitable in research labs due to the associated costs and skill training.

It is generally believed that shear rheology may dominate the deformation within the oral cavity, in particular between tongue and hard palate, but the bolus deformation within the pharyngeal region could be dominantly extensional. This was confirmed somewhat by Chen and Lolivret (2011) who observed that bolus rheology, in particular its extensional stretchability was probably more relevant than shear rheology to the ease of swallowing. In 2014, Salinas-Vázquez et al. (2014) reported that, the bolus head moving faster than the bolus tail in a computational model of the human pharynx, causing the bolus to elongate and subjected 
to extensional stresses. In 2016, He et al. (2016) showed that the extensional viscosity of a product can be used to predict several sensory attributes. It was reported that stickiness and mouth coating were better correlated to extensional viscosity than shear viscosity of the product. In 2019, Hadde and Chen (2019) hypothesised that the extensional viscosity of the fluid affects the bolus flow and is related to cohesiveness of the fluid. In that same year, Hadde et al. (2019) confirmed the relevance of the extensional viscosity to bolus swallowing. The ratio of length to the width of the bolus during Upper Esophageal Sphincter (UES) opening were measured under lateral view of videofluoroscopy swallow study (VFSS) of eight healthy individuals. It was reported that a fluid of higher extensional viscosity generally has a lower bolus aspect ratio than a fluid of lower extensional viscosity. This shows that extensional viscosity reduces the elongation of the bolus in the pharyngeal phase during swallowing, thus potentially reduced the risk of post-swallow residue due to bolus breakage (Hadde et al., 2019). On a related topic, Patel et al. (2020) showed that fluids thickened with xanthan gum based thickener (i.e. high extensional viscosity) produced a significantly shorter bolus elongation at the pharyngeal stage compared to the starch based thickener. Patel et al. (2020) measured the bolus elongation in-vitro using a physical model of artificial throat, 'Cambridge Throat'. Furthermore, a recent article by Marconati and Ramaioli (2020) examined the role of extensional rheology in-vitro study and suggested that the extensional properties can affect the transition from the oral to the pharyngeal phase of swallowing, where less elongated bolus in the oral phase lead to a fast transit and more compact bolus, which may suggest a lower risk of post-swallow residue. 
A recent review by Nishinari et al. (2019b) reported that a high cohesiveness fluid could have an important role in preventing aspiration for individuals who have dysphagia. Cohesiveness is described as the strength of the internal bonds making up the body of the product (Szczesniak, 1963). Less cohesive fluids have a risk to fracture (or splash) to multiple droplets, which may cause aspiration. Moreover, there is also a risk that some of the bolus may get caught in the pharynx as residue, requiring multiple swallows for the individuals to clear it, which may result in muscle fatigue and increase the risk of aspiration (Cichero and Murdoch, 2006). However, it must be made clear that, while an increased cohesiveness is preferred to avoid aspiration, risk of choking will become a concern if a bolus becomes too cohesive. It is suspected that for high viscosity fluids, too high cohesiveness could cause difficulty to swallow due to high resistance to stretching deformation, in particular to those who have a weak tongue muscle strength and can only produce a low oral pressure (Hadde and Chen, 2019)

Currently, there is no ready-made instrument which could be used to measure cohesiveness of semi-solid material, such as thickened fluids. It should be noted that food cohesiveness was first determined experimentally in the texture profile analysis (TPA) (Szczesniak, 1963). In this case, the cohesiveness is defined as the ratio of the energy/work required for the second compression to that for the first compression in TPA. However, this definition is only applied for soft solid foods (Nishinari and Fang, 2018, Houjaij et al., 2009, Peleg, 2006) and its scientific soundness is questioned by many texture researchers (Peleg, 2019, Nishinari et al., 2019a). A recent paper by Hadde et al. (2020a) compared and correlated the rheological parameters of thickened fluids (shear viscosity, extensional viscosity, yield stress, elastic 
modulus) with the perceived cohesiveness obtained from the sensory analysis by visual perception. It was shown that the extensional viscosity of the fluid is most-well correlated with the cohesive properties of the fluid and could be used as a feasible indication of fluid cohesiveness. Additionally, Hadde et al. (2020a) used a Texture Analyzer (TA) to develop an alternative technique to measure the cohesiveness of the fluid by measuring the droplet aspect ratio of the fluid when a fluid is extruded from the syringe at a constant speed, called syringe extrusion flow behaviour. It can be measured just at the point when the fluid breaks into droplets (experimental set up can be seen in Figure 2). Figure 3 shows the fluid drop of four different samples of thickened fluid with low shear and low extensional viscosity (sample 4), low shear and high extensional viscosity (sample 1), high shear and low extensional viscosity (sample 6), and high shear and high extensional viscosity (sample 3). It can be seen that the elongation of the fluid when extruded from the syringe is affected by the extensional viscosity of the fluid. Results obtained from the test were in high relevance with the perceived cohesiveness and the extensional viscosity of the fluid (Hadde et al., 2020a).

\section{Soft solid food}

Unlike fluid food, soft solid food is not designed for direct swallow. Soft solid food requires some oral effort for its breaking and the formation of a swallow-able bolus. Therefore, the focus of the texture properties for a soft solid food is more about the case of oral manipulation and the formation of a proper bolus. In 1988, a food oral processing model was developed by Hutchings and Lillford (1988) which describes the structural breakdown and lubrication of ingested food before swallowing takes place. Hutchings and Lillford (1988) stated that a certain degree of structure and lubrication of the bolus is required before 
swallowing can take place. The food structure must be broken down sufficiently to reduce the risks associated with choking and avoid asphyxiation. At the same time, the food must be lubricated sufficiently to improve the ease of swallowing. The oral processing that is required to meet the swallowing thresholds of both of these factors is commonly referred as the oral trajectory (Nishinari et al., 2019a) (Figure 4).

\subsection{Degree of structure and its assessment}

'Degree of structure' is a combination of bulk properties and particulate properties, such as hardness, cohesiveness, particle size, viscosity and many more. Degree of structure of a product is a generic, defined as a function of its physical properties during breakdown. The degree of structure decreases over time during mastication and needs to be reduced to a critical level before swallowing can take place.

The bolus characteristics such as particle size or cohesiveness are continuously sensed during mastication and they are important parameters in initiating swallow. In 2015, Steele et al. (2015) published a systematic review about the influence of food texture and liquid consistency on swallowing physiology and function. It was stated that with respect to food texture, properties of hardness, cohesiveness and slipperiness are important parameters both for physiological behaviours and for the patterns of bolus flow. A more recent review by Nishinari et al. (2019b) summarised the role of cohesiveness in the swallowing. Although the focus of the article was to introduce the concept of cohesiveness for a homogenous fluid bolus, the role of cohesiveness in the swallowing of heterogeneous solid foods was also briefly overviewed. 
A recent systematic review by Bonnet et al. (2019) identified the variables that can affect bolus granulometry determination. It was found that oral status, the nature of the chewed food or material and the number of chewing cycles are important factors for bolus granulometry determination. Additionally, sieving procedures based either on mechanical sieving or on image analysis could affect the bolus granulometry determination, thus should be described with precision (Bonnet et al., 2019). The particle distribution of food bolus just before swallowing was examined by Mishellany et al. (2006) using image analysis. Mishellany et al. (2006) measured the particle size distribution of two types of food, dried nuts and raw vegetables, chewed by ten healthy individuals before initiating swallow. It was reported that particle size distribution is dependent on the type of food. Nuts gave a bolus with many particles smaller than $2 \mathrm{~mm}$ in width, while raw vegetables gave more particles wider than 2 mm. Nevertheless, it was concluded that particle size of $2-4 \mathrm{~mm}$ represents the size of chewed particles that healthy adult naturally masticate for swallowing (Mishellany et al., 2006). On the contrary, studies showed that particle size of the bolus is not the main parameter to trigger swallowing for some food products, such as cheese or cereal, but rather rheological parameters, such as bolus viscosity (Yven et al., 2012, Assad-Bustillos et al., 2019a, Assad-Bustillos et al., 2019b).

With regards to food for individuals who have dysphagia, particle size of $4 \mathrm{~mm}$ is recommended by IDDSI for food served to adult for Level 5 - Minced \& Moist category, while the recommended particle size for food served to infant for Level 5 - Minced \& Moist category is $2 \mathrm{~mm}$. It is suggested to use the gaps between the tines/prongs of a standard 
metal fork (typically $4 \mathrm{~mm}$ ) to measure the particle size of Level 5 - Minced \& Moist category served to adults (Cichero et al., 2017).

During particle size reduction while chewing, food is mixed with saliva, forming a bolus that is moist and cohesive. It was stated that cohesiveness of the bolus is an important parameter in the oral processing (Prinz and Lucas, 1997, Chen and Lolivret, 2011). Nakagawa et al. (2015) reported that low cohesiveness bolus raises the risk of oral residue and aspiration due to its inappropriate rheological characteristics. As mentioned previously, food cohesiveness was first determined experimentally in the TPA. Although this technique has been widely referred and many papers have been published using this technique, Peleg (2019) questioned the scientific soundness of measurement using TPA. This is because TPA measurements are all specimens size-dependent and thus cannot be considered as intensive material properties. In addition, the measured and calculated parameters by TPA bear only a remote relationship to the same properties as understood in material science and other disciplines. In addition, recent article by Nishinari et al. (2019a) stated that the measurement of cohesiveness from TPA (ratio of the energy estimated by the area under the curve obtained from the second and first bites) should be called recoverability instead. IDDSI recommended a technique to assess the cohesiveness of the food, a spoon tilt test. The spoon tilt test is used predominantly for measures of samples in IDDSI Level 4 and Level 5 category. The sample was placed on a spoon and tilted or turned sideways to observe whether the sample is cohesive enough to hold its shape on the spoon (Cichero et al., 2017).

While the spoon tilt test is used to assess the cohesiveness of the food, results of assessment are also influenced by the adhesiveness of the food (i.e. stickiness). In food oral processing, 
adhesiveness is defined as the force required remove the material that adheres to the mouth surfaces during a normal eating (Szczesniak, 1963). As the spoon was tilted sideways, high adhesive food leave high residue on the spoon, while low adhesive food leave little residue on the spoon. It should be noted that the adhesiveness of the food with the spoon and the mouth are different. However, this technique gives some value or insight on how 'sticky' the food is. Ideally, the food should hold its shape on the spoon (i.e. cohesive) and fall easily from the spoon and leave little residue (i.e. not adhesive) when tilted sideways for individuals who have dysphagia. These characteristics provide a bolus that is moist and cohesive, but not sticky (Cichero et al., 2017). In 2008, Inagaki et al. (2008) recorded electromyograms (EMGs) from the anterior tongue and suprahyoid muscles as well as the laryngeal movement of swallowing two test foods with different hardness and adhesiveness in nine healthy participants. It was reported that high adhesive foods prolonged the duration of anterior tongue activity during swallowing (Inagaki et al., 2008). A year later, Inagaki et al. (2009) examined the effect of different food properties (hardness and adhesiveness) and body position on electromyographic amplitudes of the anterior tongue and suprahyoid muscles during swallowing in nine healthy participants. It was found that increases in the hardness and adhesiveness of the food significantly increase the anterior tongue and suprahyoid EMG activity during swallowing (Inagaki et al., 2009). On the related topic, Nakagawa et al. (2015) showed that high food adhesiveness increases the risk of pharyngeal residue due to its stickiness which may lead to aspiration after swallowing. Therefore, sticky and adhesive textures should be avoided for individuals with dysphagia. 
As we know, dysphagia occurs among individuals of all ages, but commonly with the elderly. Ageing affects the oral capability of food consumption, mainly due to the changes of their oral physiology (Laguna and Chen, 2016). A recent article by Liu et al. (2019) reported that there is a decline in maximum bite force and maximum tongue pressure with increased age among Chinese subjects. This was supported by Wang et al. (2019) that showed elderly patients with potential swallowing disorder have a significantly lower biting force maximum tongue pressure than that of healthy adults. Additionally, it was also reported that the swallowing capability showed significant correlations with both the biting force and the tongue muscle (Wang et al., 2019). This showed that individuals with dysphagia are very unlikely to consume foods of high hardness (defined as the force necessary to attain a given deformation of food at the first bite) (Nishinari et al., 2019a). Wada et al. (2017) highlighted the importance of bolus hardness in determining the appropriate number of chews, with cohesiveness and adhesiveness being secondary factors. This finding was in agreement with an article by Park et al. (2017) that compares the differences of mastication and swallowing parameters between the young adults and the elderly, varying hardness of rice food product. Four different types of rice products with different hardness were used in the study and the swallowing parameters were measured using videofluoroscopy swallow study (VFSS). It was reported that the chewing number and the oral processing time were significantly higher as the food hardness increases for both the young adults and the elderly people. However, significant difference in the pharyngeal transit time was observed only in the elderly group (Park et al., 2017), though this may be due to different viscosity in the rice product rather than the hardness of the rice. 
On the related note, a recent article by Kohyama (2020) developed a soft machine system (texture analyser equipped with an artificial tongue) to analyse the occurrence of fractures in soft food gels compressed between the tongue and hard palate. Two gellan gum gels, of which one was easily crushed and the other was difficult to crush by tongue compression and three urethane gels used as artificial tongues with different hardness and modulus were selected in the study. The food gel and the artificial tongue were deformed, leading to the fracturing of food gels alone. It was reported that the fracture probability of food gels was lower for the combination of harder food gels and softer artificial tongues, as softer materials can deform to a larger extent.

A simple and practical test of food hardness was developed by IDDSI for assessing foods that fall into IDDSI Level $5-7$ called fork pressure test (Cichero et al., 2017). This test is performed by placing the thumb onto the bowl of the fork (just below the prongs) onto the food sample and applies pressure until the thumb nail blanches noticeably to white to observe its behaviour. Blanching occurs has been quantified at approximately $17 \mathrm{kPa}$ (Cichero et al., 2017) and this pressure is comparable with typical tongue pressure used during swallowing (Steele et al., 2014, Fei et al., 2013).

\subsection{Degree of lubrication and its assessment}

Lubrication refers to a physical phenomenon when a fluid is between two interacting solid surfaces in a relative movement. For food oral processing, 'degree of lubrication' is the perception associated with moisture and juiciness, such as moisture content and slipperiness. It is a combination of moisture initially present in the mouth, product's moisture content, salivary flow rate and other factors such as presence of fat. Degree of lubrication generally 
increases over time during mastication and it must be above a certain value before swallowing can take place (Hutchings and Lillford, 1988). Degree of lubrication may include two types of surface movement: a proper lubrication between food particles and a proper lubrication between a cohesive bolus and oral surface. The former is important in controlling the deformation of the bolus, the latter determines bolus flowability within the swallowing tract. Both types of lubrication provide reflection of the stretchability and cohesiveness of the bolus.

With no doubt at all, saliva is the most essential ingredient for lubrication. Salivation moistens the food bolus and assists food softening, structure breakdown and dilution (AssadBustillos et al., 2019a, Assad-Bustillos et al., 2019b, Panouillé et al., 2014). For cereal products such as bread or foods enriched with starch, the effect of saliva will be more significant. In addition to moistening and coating effect, the interactions of salivary $\alpha$ amylase will lead to immediate degradation of starch components, causing structural breakdown (for solid or soft solid food) and/or significant viscosity reduction (for fluid food) (Joubert et al., 2017, van Aken et al., 2007, Ferry et al., 2004). In this case, the dynamics of bolus formation will be hugely different and, therefore, a different strategy is needed for the initiation and controlling of bolus swallowing.

One unique property of saliva is its incredibly strong interfacial film, formed from multilayer of protein that forms on surface and interfaces which confer saliva lubrication properties, increasing the slipperiness in the oral phase (Proctor et al., 2005). Saliva coating is essential for lubrication and protection of soft and hard tissues (Mosca and Chen, 2017). Seo et al. (2007) defined slipperiness as the degree of slide for the food bolus through the mucosal 
surface of the oropharynx. Tribology is a promising field which takes into consideration the effect of lubrication by saliva, surface properties and frictional forces between food and oral parts (e.g. tongue and hard palate) (Sethupathy et al., 2020). Tribometers are commonly used in research labs to measure the friction coefficient of the material with fundamental precision. However, a conventional tribometer is usually made of hard surfaces (e.g. metal) which does not reflect real oral conditions. A range of tribometers have been designed and conventional texture measurement devices are being modified with accessories to measure the tribological behaviour to comprehend texture using novel approaches (Sethupathy et al., 2020). The use of soft surfaces, such as hydrophobic or hydrophilic polydimethylsiloxane (PDMS) has shown promising capabilities of tribological techniques for soft tribology (Dresselhuis et al., 2008, Sarkar et al., 2019). A recent review article by Rudge et al. (2019) summarised recently developed experimental methods and techniques to overcome challenges in the field of soft tribology including mimicking in-mouth conditions.

A recent work by Mo et al. (2019) reported a new experimental set up for in situ oral lubrication measurement and determining oral lubrication as influenced by food consumption in relation to texture and mouth-feel. The design was based on a mechanical coupling between a texture analyser for friction force measurement and Iowa Oral Performance Instrument (IOPI) for normal load determination, and on a simultaneous digitizing of signals from both devices (Figure 5). It was reported that the oral friction coefficient showed a good correlation with the sensory intensity perception of astringency and slipperiness (Mo et al., 2019). Another recent article by Shimasaki et al. (2019) developed a novel method to quantitatively evaluate slipperiness and frictional forces of solid coating formulation for 
medicine and correlate these parameters with the ease of swallowing. Shimasaki et al. (2019) used the tribological characteristics analyser to measure the friction force of the sample by moving the sample stage horizontally, while applying a constant load vertically to the sample (see Figure 6). The purpose was to measure in vitro the frictional resistance generated between the samples and the oral cavity or gastrointestinal mucosa. It was reported that difficulty in swallowing is reduced with increasing slipperiness of the samples (Shimasaki et al., 2019).

During mastication, saliva increases the moisture content of the bolus. Yven et al. (2006) hypothesised that the level of moisture is important in triggering swallow which fits with the food oral processing model developed by Hutchings and Lillford (1988), which describes the structural breakdown and lubrication of ingested food before swallowing can be initiated. An article by Motoi et al. (2013) studied how bolus moisture content changes during oral processing of solid foods. Motoi et al. (2013) measured the moisture content of the bolus during mastication for biscuits and Dutch cake. It was reported that moisture content of boluses during mastication increased linearly at a rate depending on the type of foods (biscuit is $35.4 \%$, Dutch cake is $43.6 \%$ ). This finding was in agreement with the results found by Loret et al. (2011) who reported that the moisture content of food boluses was around $50 \%$, regardless of the types of the cereal. Additionally, Lorieau et al. (2018) reported that the bolus formation of whipped cheese was harder than soft or processed cheese because it required more saliva for the bolus formation. This type of product was characterised as a dry and sticky texture. On a related note, the effect of initial food moisture content on the bolus moisture content at swallowing point was observed (Motoi et al., 2013). It was reported that 
the bolus moisture content at the point of swallowing increased with increasing initial moisture content of foods. However, the total saliva addition to boluses is less with increasing initial moisture content of foods because less saliva was required to enable the bolus to reach swallowing consistency (Motoi et al., 2013). This is particularly relevant for individuals who have dysphagia. It was reported that individuals with dysphagia are typically dehydrated and present with dry mouth (Xerostomia) (Stokes et al., 2013). Therefore, it is recommended for individuals with dysphagia to consume food with high initial moisture content.

\section{Conclusions}

Investigations of food oral processing are improving our understanding of the relevant parameters in swallowing, specifically for dysphagia management. At the outset of this review, we identified several points for our investigations regarding the relevant parameters of swallowing for dysphagia management. We conclude that thickened fluids and texture-modified foods have different controlling rheological or textural properties for safe swallowing. Table 1 summarised the important parameters of thickened fluids and texture-modified foods regarding texture assessment for dysphagia management. Important parameters of thickened fluids are generally related with the flow of bolus in the pharyngeal stage. Both shear and extensional rheology of thickened fluids are important in swallowing. Shear viscosity slows down the flow of the bolus in the pharynx, while extensional viscosity helps to regulate bolus elongation in the pharyngeal phase, potentially reducing the risk of post-swallow residue caused by bolus breakage. On the other hand, important parameters of texture-modified foods are generally related with the bolus preparation in the oral stage. These parameters can be divided into two factors, degree of structure and degree of 
lubrication. Degree of structure is a combination of textural properties and particulate properties of the bolus, such as hardness, cohesiveness, adhesiveness and particle size. Degree of lubrication is a combination of surface properties and perception of moisture and juiciness of the bolus, such as moisture content and slipperiness.

This review serves as the first step to identify key textural parameters that are important for safe and controlled bolus swallow and to develop objective measurement techniques in order to ensure quality control of thickened fluids and texture-modified foods for dysphagia management.

This article is protected by copyright. All rights reserved. 


\section{Compliance with Ethical Standards}

Funding: The financial support of National Natural Science Foundation of China (Grant No. 31871885) is gratefully appreciated.

Conflict of interest: The authors declare that they do not have any conflict of interest. Jianshe Chen declares that he is a board member of IDDSI, but this work was not committed by IDDSI.

Ethical approval: This article does not contain any studies with human participants or animals performed by any of the authors.

This article is protected by copyright. All rights reserved. 


\section{References}

Althaus, C. B. (2002). Dealing with dysphagia. Food And Food Industries, 15(3), 58.

Assad-Bustillos, M., Tournier, C., Feron, G., Guessasma, S., Reguerre, A. L., \& Della Valle, G. (2019a). Fragmentation of two soft cereal products during oral processing in the elderly: Impact of product properties and oral health status. Food Hydrocolloids, 91, 153-165.

Assad-Bustillos, M., Tournier, C., Septier, C., Della Valle, G., \& Feron, G. (2019b). Relationships of oral comfort perception and bolus properties in the elderly with salivary flow rate and oral health status for two soft cereal foods. Food Research International, 118, $13-21$.

Atherton, M., Bellis-Smith, N., Cichero, J. A. Y., \& Suter, M. (2007). Texture-modified foods and thickened fluids as used for individuals with dysphagia: Australian standardised labels and definitions. Nutrition \& Dietetics, 64, S53-S76.

Barbon, C. E. A., \& Steele, C. M. (2018). Thickened Liquids for Dysphagia Management: a Current Review of the Measurement of Liquid Flow. Current Physical Medicine and Rehabilitation Reports, 6(4), 220-226.

Barczi, S. R., Sullivan, P. A., \& Robbins, J. A. (2000). How Should Dysphagia Care of Older Adults Differ? Establishing Optimal Practice Patterns. Semin Speech Lang, 21(04), 03470364.

This article is protected by copyright. All rights reserved. 
Bingjie, L., Tong, Z., Xinting, S., Jianmin, X., \& Guijun, J. (2010). Quantitative videofluoroscopic analysis of penetration-aspiration in post-stroke patients. Neurology India, 58(1), 42-47.

Bonnet, G., Batisse, C., Peyron, M.-A., Nicolas, E., \& Hennequin, M. (2019). Which variables should be controlled when measuring the granulometry of a chewed bolus? A systematic review. Journal of Texture Studies, 50(3), 194-216.

Brito-de la Fuente, E., Turcanu, M., Ekberg, O., \& Gallegos, C. (2017). Rheological Aspects of Swallowing and Dysphagia: Shear and Elongational Flows. Dysphagia: Diagnosis and Treatment, 687-716.

Cabre, M., Serra-Prat, M., Palomera, E., Almirall, J., Pallares, R., \& Clavé, P. (2010). Prevalence and prognostic implications of dysphagia in elderly patients with pneumonia. Age and Ageing, 39(1), 39-45.

Chen, J. (2009). Food oral processing-A review. Food Hydrocolloids, 23(1), 1-25.

Chen, J., \& Lolivret, L. (2011). The determining role of bolus rheology in triggering a swallowing. Food Hydrocolloids, 25(3), 325-332.

Cho, H.-M., Yoo, W., \& Yoo, B. (2012). Steady and dynamic rheological properties of thickened beverages used for dysphagia diets. Food Science and Biotechnology, 21(6), 17751779.

Cichero, J., Lam, P., Steele, C. M., Hanson, B., Chen, J., Dantas, R. O., . . Stanschus, S. (2017). Development of International Terminology and Definitions for Texture-Modified

This article is protected by copyright. All rights reserved. 
Foods and Thickened Fluids Used in Dysphagia Management: The IDDSI Framework. Dysphagia, 32(2), 293-314.

Cichero, J., \& Murdoch, B. (Eds.). (2006). Dysphagia Foundation, theory and practice. West Sussex: Wiley.

Cichero, J. A. Y., Jackson, O., Halley, P. J., \& Murdoch, B. E. (2000). Which one of these is not like the others? An inter-hospital study of the viscosity of thickened fluids. Journal of Speech, Language and Hearing Research, 43(2), 537-547.

Cichero, J. A. Y., Lam, P. T. L., Chen, J., Dantas, R. O., Duivestein, J., Hanson, B., . . . Vanderwegen, J. (2020). Release of updated International Dysphagia Diet Standardisation Initiative Framework (IDDSI 2.0). Journal of Texture Studies, 51(1), 195 - 196.

Cichero, J. Y., Steele, C., Duivestein, J., Clavé, P., Chen, J., Kayashita, J., . . . Murray, J. (2013). The Need for International Terminology and Definitions for Texture-Modified Foods and Thickened Liquids Used in Dysphagia Management: Foundations of a Global Initiative. Current Physical Medicine and Rehabilitation Reports, 1(4), 280-291.

Dantas, R., Kern, M., Massey, B., Dodds, W., Kahrilas, P., Brasseur, J., . . . Lang, I. (1990). Effect of swallowed bolus variables on oral and pharyngeal phases of swallowing. American Journal of Physiology - Gastrointestinal and Liver Physiology, 258(5 Pt 1).

Dresselhuis, D. M., de Hoog, E. H. A., Cohen Stuart, M. A., \& van Aken, G. A. (2008). Application of oral tissue in tribological measurements in an emulsion perception context. Food Hydrocolloids, 22(2), 323-335. 
Fei, T., Polacco, R. C., Hori, S. E., Molfenter, S. M., Peladeau-Pigeon, M., Tsang, C., \& Steele, C. M. (2013). Age-related Differences in Tongue-Palate Pressures for Strength and Swallowing Tasks. Dysphagia, 28(4), 575-581.

Ferry, A.-L., Hort, J., Mitchell, J. R., Lagarrigue, S., \& Pamies, B. V. (2004). Effect of Amylase Activity on Sarch Paste Viscosity and its Implications for Flavor Perception. Journal of Texture Studies, 35(5), 511-524.

Funami, T. (2016). The Formulation Design of Elderly Special Diets. Journal of Texture Studies, 47(4), 313-322.

Garcia, J. M., Chambers, E., Matta, Z., \& Megan, C. (2008). Serving Temperature Viscosity Measurements of Nectar- and Honey- Thick Liquids. Dysphagia, 23(1), 65 - 75

Goldfield, E., Smith, V., Buonomo, C., Perez, J., \& Larson, K. (2013). Preterm Infant Swallowing of Thin and Nectar-Thick Liquids: Changes in Lingual-Palatal Coordination and Relation to Bolus Transit. Dysphagia, 28(2), 234-244.

Hadde, E. K., \& Chen, J. (2019). Shear and extensional rheological characterization of thickened fluid for dysphagia management. Journal of Food Engineering, 245, 18-23.

Hadde, E. K., Chen, W., \& Chen, J. (2020a). Cohesiveness visual evaluation of thickened fluids. Food Hydrocolloids, 101, 105522.

Hadde, E. K., Cichero, J. A. Y., \& Nicholson, T. M. (2015a). Viscosity of thickened fluids that relate to the Australian National Standards. International Journal of Speech-Language Pathology, 1-9.

This article is protected by copyright. All rights reserved. 
Hadde, E. K., Cichero, J. A. Y., Zhao, S., Chen, W., \& Chen, J. (2019). The Importance of Extensional Rheology in Bolus Control during Swallowing. Scientific Reports, 9(1), 16106.

Hadde, E. K., Nicholson, T. M., \& Cichero, J. A. Y. (2015b). Rheological characterisation of thickened fluids under different temperature, $\mathrm{pH}$ and fat contents. Nutrition \& Food Science, 45(2), 270-285.

Hadde, E. K., Nicholson, T. M., \& Cichero, J. A. Y. (2020b). Evaluation of Thickened Fluids Used in Dysphagia Management Using Extensional Rheology. Dysphagia, 35(2), 242-252.

Hadde, E. K., Nicholson, T. M., Cichero, J. A. Y., \& Deblauwe, C. (2015c). Rheological characterisation of thickened milk components (protein, lactose and minerals). Journal of Food Engineering, 166(0), 263-267.

Hanson, B. (2016). A review of diet standardization and bolus rheology in the management of dysphagia. Curr Opin Otolaryngol Head Neck Surg, 24(3), 183-190.

He, Q., Hort, J., \& Wolf, B. (2016). Predicting sensory perceptions of thickened solutions based on rheological analysis. Food Hydrocolloids, 61, 221-232.

Houjaij, N., Dufresne, T., Lachance, N., \& Ramaswamy, H. S. (2009). Textural Characterization of Pureed Cakes Prepared for the Therapeutic Treatment of Dysphagic Patients. International Journal of Food Properties, 12(1), 45-54.

Hutchings, J. B., \& Lillford, P. J. (1988). The perception of food texture - the philosophy of the breakdown path. Journal of Texture Studies, 19(2), 103-115.

This article is protected by copyright. All rights reserved. 
Inagaki, D., Miyaoka, Y., Ashida, I., \& Yamada, Y. (2008). Influence of food properties and body posture on durations of swallowing-related muscle activities. Journal of Oral Rehabilitation, 35(9), 656-663.

Inagaki, D., Miyaoka, Y., Ashida, I., \& Yamada, Y. (2009). Influence of food properties and body position on swallowing-related muscle activity amplitude. Journal of Oral Rehabilitation, 36(3), 176-183.

Joubert, M., Septier, C., Brignot, H., Salles, C., Panouille, M., Feron, G., \& Tournier, C. (2017). Chewing breads: impact on alpha-amylase secretion and oral digestion. Food and Function, 8(2), 607-614.

Kohyama, K. (2020). Compression test of soft gellan gels using a soft machine equipped with a transparent artificial tongue. Journal of Texture Studies, 1 - 10.

Laguna, L., \& Chen, J. (2016). The eating capability: Constituents and assessments. Food Quality and Preference, 48, 345-358.

Leonard, R., \& Kendall, K. (Eds.). (2013). Dysphagia Assessment and Treatment Planning: A Team Approach (Third ed.). San Diego: Plural Publishing.

Liu, H., Qin, L., Wu, Y., van der Glas, H. W., Chen, J., \& Wang, X. (2019). Oral physiological characteristics among Chinese subjects in the eastern region of China. Arch Oral Biol, 108, 104539.

Logemann, J. A. (2007). Swallowing Disorder. Best Practice \& Research Clinical Gastroenterology, 21(4), 563 - 573.

This article is protected by copyright. All rights reserved. 
Logemann, J. A. (2014). Critical Factors in the Oral Control Needed for Chewing and Swallowing. Journal of Texture Studies, 45(3), 173-179.

Logemann, J. A. (Ed.). (1998). Evaluation and Treatment of Swallowing Disorders (2 ed.). Austin: PRO-ED, Incorporated.

Loret, C., Walter, M., Pineau, N., Peyron, M.-A., Hartmann, C., \& Martin, N. (2011). Physical and related sensory properties of a swallowable bolus. Physiology \& Behavior, 104, 855-864.

Lorieau, L., Septier, C., Laguerre, A., Le Roux, L., Hazart, E., Ligneul, A., . . Labouré, H. (2018). Bolus quality and food comfortability of model cheeses for the elderly as influenced by their texture. Food Research International, 111, 31-38.

Macosko, C. W. (1994). Rheology: Principles, Measurements, and Applications: WileyVCH.

Marconati, M., \& Ramaioli, M. (2020). The role of extensional rheology in the oral phase of swallowing: an in vitro study [10.1039/C9FO02327E]. Food \& Function, 11(5), 4363-4375.

Miller, J., \& Watkin, K. (1996). The influence of bolus volume and viscosity on anterior lingual force during the oral stage of swallowing. Dysphagia, 11(2), 117-124.

Mishellany, A., Woda, A., Labas, R., \& Peyron, M.-A. (2006). The Challenge of Mastication: Preparing a Bolus Suitable for Deglutition. Dysphagia, 21(2), 87-94.

Mo, L., Chen, J., \& Wang, X. (2019). A novel experimental set up for in situ oral lubrication measurements. Food Hydrocolloids, 95, 396-405.

This article is protected by copyright. All rights reserved. 
Mosca, A. C., \& Chen, J. (2017). Food-saliva interactions: Mechanisms and implications. Trends in Food Science \& Technology, 66, 125-134.

Motoi, L., Morgenstern, M. P., Hedderley, D. I., Wilson, A. J., \& Balita, S. (2013). Bolus Moisture Content of Solid Foods during Mastication. Journal of Texture Studies, 44(6), 468479.

Nakagawa, K., Matsuo, K., Shibata, S., Inamoto, Y., Ito, Y., Abe, K., . . . Saitoh, E. (2015). Efficacy of a novel training food based on the process model of feeding for mastication and swallowing - A preliminary study in elderly individuals living at a residential facility —. Japanese Journal of Comprehensive Rehabilitation Science, 72-78.

Namasivayam-MacDonald, A. M., Barbon, C. E. A., \& Steele, C. M. (2018). A review of swallow timing in the elderly. Physiology \& Behavior, 184, 12-26.

National Dysphagia Diet Task Force. (2002). National Dysphagia Diet: Standardization for Optimal Care (illustrated ed.). Chicago: American Dietic Association, 2002

Newman, R., Vilardell, N., Clavé, P., \& Speyer, R. (2016). Effect of Bolus Viscosity on the Safety and Efficacy of Swallowing and the Kinematics of the Swallow Response in Patients with Oropharyngeal Dysphagia: White Paper by the European Society for Swallowing Disorders (ESSD). Dedicated to advancing the art and science of deglutology, 31(2), 232249.

Nishinari, K., \& Fang, Y. (2018). Perception and measurement of food texture: Solid foods. $J$ Texture Stud, 49(2), 160-201.

This article is protected by copyright. All rights reserved. 
Nishinari, K., Fang, Y., \& Rosenthal, A. (2019a). Human oral processing and texture profile analysis parameters: Bridging the gap between the sensory evaluation and the instrumental measurements. Journal of Texture Studies, 50(5), 369-380.

Nishinari, K., Turcanu, M., Nakauma, M., \& Fang, Y. (2019b). Role of fluid cohesiveness in safe swallowing. npj Science of Food, 3(1), 5.

Ong, J. J.-X., Steele, C. M., \& Duizer, L. M. (2018). Sensory characteristics of liquids thickened with commercial thickeners to levels specified in the International Dysphagia Diet Standardization Initiative (IDDSI) framework. Food Hydrocolloids, 79, 208-217.

Panouillé, M., Saint-Eve, A., Déléris, I., Le Bleis, F., \& Souchon, I. (2014). Oral processing and bolus properties drive the dynamics of salty and texture perceptions of bread. Food Research International, 62, 238-246.

Park, H. S., Kim, D.-K., Lee, S. Y., \& Park, K.-H. (2017). The effect of aging on mastication and swallowing parameters according to the hardness change of solid food. Journal of Texture Studies, 48(5), 362-369.

Patel, S., McAuley, W. J., Cook, M. T., Sun, Y., Hamdy, S., \& Liu, F. (2019). The Swallowing Characteristics of Thickeners, Jellies and Yoghurt Observed Using an In Vitro Model. Dysphagia, 35, 685-695.

Peleg, M. (2006). On fundamental issues in texture evaluation and texturization-A view. Food Hydrocolloids, 20(4), 405-414.

This article is protected by copyright. All rights reserved. 
Peleg, M. (2019). The instrumental texture profile analysis revisited. Journal of Texture Studies, 50(5), 362-368.

Popa Nita, S., Murith, M., Chisholm, H., \& Engmann, J. (2013). Matching the Rheological Properties of Videofluoroscopic Contrast Agents and Thickened Liquid Prescriptions. Dysphagia, 28(2), 245-252.

Prinz, J. F., \& Lucas, P. W. (1997). An optimization model for mastication and swallowing in mammals. Proceedings. Biological sciences, 264(1389), 1715-1721.

Proctor, G. B., Hamdan, S., Carpenter, G. H., \& Wilde, P. (2005). A statherin and calcium enriched layer at the air interface of human parotid saliva. Biochem J, 389(Pt 1), 111-116.

Rao, M. A. (1977). Rheology of liquid foods - a review. Journal of Texture Studies, 8(2), 135-168.

Reimers-Neils, L., Logemann, J., \& Larson, C. (1994). Viscosity effects on EMG activity in normal swallow. Dysphagia, 9(2), 101-106.

Robbins, J., Hamilton, J., Lof, G., \& Kempster, G. (1992). Oropharyngeal swallowing in normal adults of different ages. Gastroenterology, 103, 823 - 829.

Rudge, R. E. D., Scholten, E., \& Dijksman, J. A. (2019). Advances and challenges in soft tribology with applications to foods. Current Opinion in Food Science, 27, 90-97.

Salinas-Vázquez, M., Vicente, W., Brito-de la Fuente, E., Gallegos, C., Márquez, J., \& Ascanio, G. (2014). Early Numerical Studies on the Peristaltic Flow through the Pharynx. Journal of Texture Studies, 45(2), 155-163.

This article is protected by copyright. All rights reserved. 
Sarkar, A., Andablo-Reyes, E., Bryant, M., Dowson, D., \& Neville, A. (2019). Lubrication of soft oral surfaces. Current Opinion in Colloid \& Interface Science, 39, 61-75.

Seo, H.-S., Hwang, I. K., Han, T. R., \& Kim, I. S. (2007). Sensory and Instrumental Analysis for Slipperiness and Compliance of Food during Swallowing. Journal of Food Science, 72(9), S707-S713.

Sethupathy, P., Moses, J. A., \& Anandharamakrishnan, C. (2020). Food Oral Processing and Tribology: Instrumental Approaches and Emerging Applications. Food Reviews International, 1-34.

Shimasaki, M., Murayama, N., Fujita, Y., Nakamura, A., \& Harada, T. (2019). A novel method to quantitatively evaluate slipperiness and frictional forces of solid oral dosage forms and to correlate these parameters with ease of swallowing. Journal of Drug Delivery Science and Technology, 53, 101141.

Sopade, P. A., Halley, P. J., Cichero, J. A. Y., \& Ward, L. C. (2007). Rheological characterisation of food thickeners marketed in Australia in various media for the management of dysphagia. I: Water and cordial. Journal of Food Engineering, 79(1), 69-82.

Sopade, P. A., Halley, P. J., Cichero, J. A. Y., Ward, L. C., Hui, L. S., \& Teo, K. H. (2008a). Rheological characterisation of food thickeners marketed in Australia in various media for the management of dysphagia. II. Milk as a dispersing medium. Journal of Food Engineering, 84(4), 553-562.

This article is protected by copyright. All rights reserved. 
Sopade, P. A., Halley, P. J., Cichero, J. A. Y., Ward, L. C., Liu, J., \& Varliveli, S. (2008b). Rheological characterization of food thickeners marketed in Australia in various media for the management of dysphagia. III. Fruit juice as a dispersing medium. Journal of Food Engineering, 86(4), 604-615.

Steele, C., Molfenter, S., Péladeau-Pigeon, M., Polacco, R., \& Yee, C. (2014). Variations in Tongue-Palate Swallowing Pressures When Swallowing Xanthan Gum-Thickened Liquids. Dysphagia, 1-7.

Steele, C. M. (2015). The Blind Scientists and the Elephant of Swallowing: A Review of Instrumental Perspectives on Swallowing Physiology. Journal of Texture Studies, 46, 122137.

Steele, C. M., Alsanei, W. A., Ayanikalath, S., Barbon, C. E. A., Chen, J., Cichero, J. A. Y., . . . Wang, H. (2015). The Influence of Food Texture and Liquid Consistency Modification on Swallowing Physiology and Function: A Systematic Review. Dysphagia, 30(1), 2-26.

Stokes, J. R., Boehm, M. W., \& Baier, S. K. (2013). Oral processing, texture and mouthfeel: From rheology to tribology and beyond. Current Opinion in Colloid \& Interface Science, 18(4), 349-359.

Szczesniak, A. S. (1963). Classification of Textural Characteristicsa. Journal of Food Science, 28(4), 385-389.

This article is protected by copyright. All rights reserved. 
Taniguchi, H., Tsukada, T., Ootaki, S., Yamada, Y., \& Inoue, M. (2008). Correspondence between food consistency and suprahyoid muscle activity, tongue pressure, and bolus transit times during the oropharyngeal phase of swallowing. J Appl Physiol (1985), 105(3), 791-799.

van Aken, G. A., Vingerhoeds, M. H., \& de Hoog, E. H. A. (2007). Food colloids under oral conditions. Current Opinion in Colloid \& Interface Science, 12(4), 251-262.

Wada, S., Goto, T., Fujimoto, K., Watanabe, M., Nagao, K., Nakamichi, A., \& Ichikawa, T. (2017). Changes in food bolus texture during mastication. Journal of Texture Studies, 48(2), 171-177.

Wang, X., Zheng, G., Su, M., Chen, Y., Xie, H., Han, W., . . . Chen, J. (2019). Biting force and tongue muscle strength as useful indicators for eating and swallowing capability assessment among elderly patients. Food Science and Human Wellness, 8(2), 149-155.

Waqas, M. Q., Wiklund, J., Altskär, A., Ekberg, O., \& Stading, M. (2017). Shear and extensional rheology of commercial thickeners used for dysphagia management. Journal of Texture Studies, 48(6), 507-517.

Whelan, K. (2001). Inadequate fluid intakes in dysphagic acute stroke. Clinical Nutrition, 20(5), 423-428.

Yven, C., Bonnet, L., Cormier, D., Monier, S., \& Mioche, L. (2006). Impaired mastication modifies the dynamics of bolus formation. European Journal of Oral Sciences, 114(3), 184190.

This article is protected by copyright. All rights reserved. 
Yven, C., Patarin, J., Magnin, A., Laboure, H., Repoux, M., Guichard, E., \& Feron, G. (2012). Consequences of Individual Chewing Stretegies on Bolus Rheological Properties at the Swallowing Threshold Journal of Texture Studies, 43(4), 309-318.

This article is protected by copyright. All rights reserved. 


\section{Figure Legends}

Figure 1: An illustration showing fluid elements movement in a shear (A) and an extensional flow (B).

Figure 2: Schematic and photograph of syringe extrusion flow behaviour from Hadde et al. (2020a).

Figure 3: Visual perception of flow behaviour of sample 1 (RTC 1.50\%), sample 3 (RTC 8.50\%), sample 4 (THU 4.50\%) and sample 6 (THU 6.50\%) when extruded from the syringe from Hadde et al. (2020a). RTC = Resource ThickenUp Clear (xanthan gum based thickener), THU = ThickenUp (starch-based thickener).

Figure 4: Food oral processing model from Nishinari et al. (2019a). Food is swallowed after reaching two thresholds of 'degree of structure' and 'degree of lubrication'. The rectangle represents a 'swallowing bar' where the two thresholds have been reached.

Figure 5: Schematic illustration of the experimental setup for in situ measurements of oral friction based on the synchronisation of a texture analyser and a tongue pressure measuring device, IOPI developed by Mo et al. (2019)

Figure 6: A schematic representation of the measurement procedure of maximum static frictional force and kinetic frictional force developed by Shimasaki et al. (2019).

Table 1. Summary of the important parameters of thickened fluids and texture-modified foods regarding texture assessment for dysphagia management 


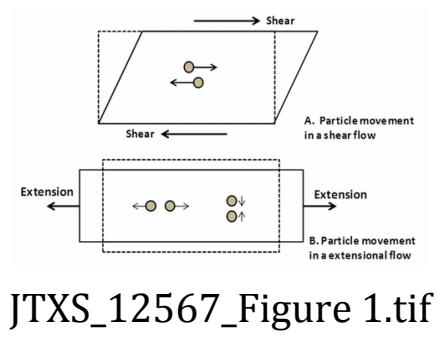

This article is protected by copyright. All rights reserved. 


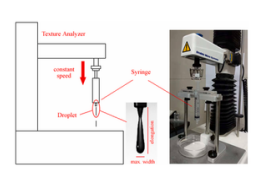

JTXS_12567_Figure 2.tif

This article is protected by copyright. All rights reserved. 

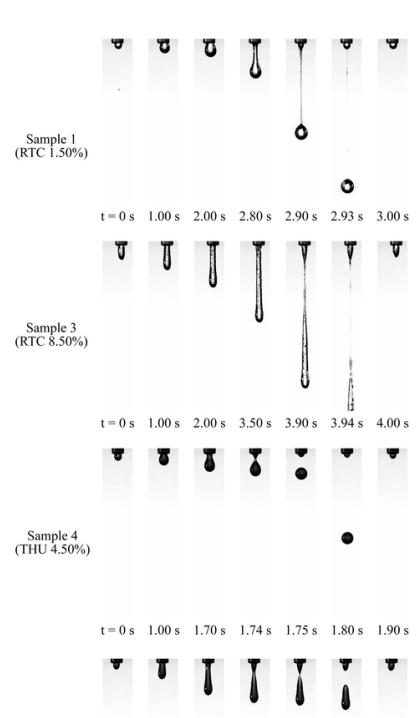

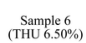

JTXS_12567_Figure 3.tif

This article is protected by copyright. All rights reserved. 


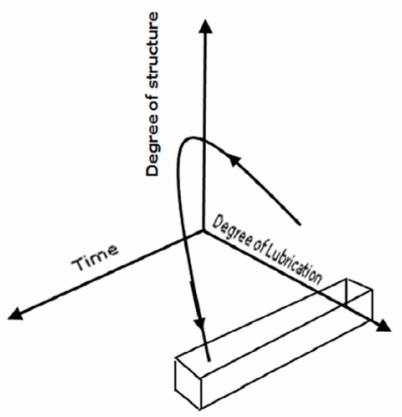

JTXS_12567_Figure 4.tif 


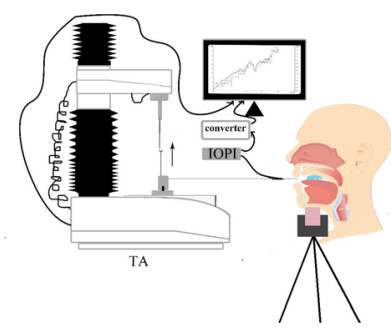

JTXS_12567_Figure 5.tif

This article is protected by copyright. All rights reserved. 


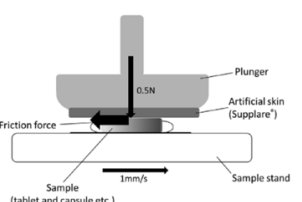

JTXS_12567_Figure 6.tif

This article is protected by copyright. All rights reserved. 
Table 1: Summary of the important parameters of thickened fluids and texture-modified foods regarding texture assessment for dysphagia management

\begin{tabular}{|c|c|}
\hline Thickened Fluids & Texture-Modified Foods \\
\hline \multirow{3}{*}{$\begin{array}{l}\text { Shear viscosity (thickness) } \\
\text { - Slows down the flow of the bolus in } \\
\text { the pharynx } \\
\text { - Need to be in a suitable range } \\
\text { - Fluids that too thin may result in } \\
\text { pneumonia, while over-thickened } \\
\text { fluids may result in aspiration due to } \\
\text { residue } \\
\text { Measure with shear rheometer, } \\
\text { line-spread test, Bostwick } \\
\text { consistometry, IDDSI syringe flow } \\
\text { test }\end{array}$} & $\begin{array}{l}\text { Particle size } \\
\begin{array}{l}\text { - } \\
\text { - } \\
\text { Sarameter to trigger swallowing particle size is recommended } \\
\text { for dysphagic patients ( }<4 \mathrm{~mm} \text { for } \\
\text { adult, }<2 \text { mm for infant) } \\
\text { - } \text { Measure with IDDSI fork test }\end{array}\end{array}$ \\
\hline & $\begin{array}{l}\text { Food Cohesiveness } \\
\text { - Low cohesiveness bolus raises the } \\
\text { risk of oral residue } \\
\text { - Measure with texture analyzer, } \\
\text { IDDSI spoon tilt test }\end{array}$ \\
\hline & $\begin{array}{l}\text { Adhesiveness (stickiness) } \\
\text { - Prolonged the duration of anterior } \\
\text { tongue activity during swallowing }\end{array}$ \\
\hline \multirow[t]{2}{*}{$\begin{array}{l}\text { Yield stress } \\
\text { - Affect the total amount of tongue } \\
\text { pressure required to initiate flow of } \\
\text { the fluid for swallow reflexion } \\
\text { - Measure with shear rheometer }\end{array}$} & $\begin{array}{l}\text { - Sticky bolus increases the risk of } \\
\text { pharyngeal residue } \\
\text { - Sticky and adhesive textures should } \\
\text { be avoided for dysphagic patients } \\
\text { - Measure with texture analyzer, } \\
\text { IDDSI spoon tilt test }\end{array}$ \\
\hline & $\begin{array}{l}\text { Firmness (hardness) } \\
\text { - Affect the appropriate number of } \\
\text { chews and oral processing time for } \\
\text { swallowing } \\
\text { - Soft food is recommended for } \\
\text { dysphagic patients } \\
\text { Measure with texture analyzer, } \\
\text { IDDSI fork pressure test }\end{array}$ \\
\hline $\begin{array}{l}\text { Extensional viscosity (cohesiveness) } \\
\text { - Reduces elongation of the bolus in } \\
\text { the pharyngeal phase during } \\
\text { swallowing, potentially reduce the } \\
\text { risk of post-swallow residue caused } \\
\text { by bolus breakage } \\
\text { - Less cohesive fluids have a risk of }\end{array}$ & $\begin{array}{l}\text { Friction coefficient (slipperiness) } \\
\text { - } \quad \text { Determines bolus flowability within } \\
\text { the swallowing tract } \\
\text { - } \text { Protect soft and hard tissue } \\
\text { - Increasing slipperiness of the bolus } \\
\text { - } \text { reduced difficulty in swallowing } \\
\text { Measure with tribometer, modified }\end{array}$ \\
\hline
\end{tabular}




\begin{tabular}{|l|rl|}
\hline fracture to multiple droplets, which & \multicolumn{2}{|c|}{ texture analyzer } \\
\cline { 2 - 2 } $\begin{array}{l}\text { may cause aspiration, while risk of } \\
\text { choking become a concern if a bolus }\end{array}$ & Moisture content \\
becomes too cohesive & - & Important in triggering swallow \\
Measure with extensional rheometer, & - & High initial moisture content food \\
syringe extrusion flow behaviour & & $\begin{array}{l}\text { required less saliva to reach } \\
\text { swallowing consistency }\end{array}$ \\
& - $\begin{array}{l}\text { High initial moisture content food is } \\
\text { recommended for dysphagic patients }\end{array}$ \\
\hline
\end{tabular}

This article is protected by copyright. All rights reserved. 


\section{University Library}

\section{- M M N E R VA A gateway to Melbourne's research publications}

Minerva Access is the Institutional Repository of The University of Melbourne

Author/s:

Hadde, EK;Chen, J

Title:

Texture and texture assessment of thickened fluids and texture-modified food for dysphagia management

Date:

2020-11-18

Citation:

Hadde, E. K. \& Chen, J. (2020). Texture and texture assessment of thickened fluids and texture-modified food for dysphagia management. JOURNAL OF TEXTURE STUDIES, 52 (1), pp.4-15. https://doi.org/10.1111/jtxs.12567.

Persistent Link:

http://hdl.handle.net/11343/276628 